The third block of training is a practical field medical exercise with residents performing their roles as disaster or field medical officers. The field environment includes a field hospital with ground and air evacuation capabilities, as well as all the necessary paramedical and nursing personnel to support it. The residents then assess, perform triage, and initiate resuscitative and therapeutic measures upon moulaged casualties. The residents also take turns assuming paramedical roles in order to better appreciate the initial assessment, care and evacuation mission performed by paramedical personnel in combat or disaster situations. The entire field exercise lasts 3 to 4 days and requires that appropriate preventive measures be observed similar to that required of disaster operations. The residents there have exposure to the logistical and supply problems of such a relief exercise. This area is one in which they must excel to effectively manage such an operation successfully.

The final portion of the operational medicine rotation includes an area wide disaster drill. The particular disaster situation is modified in order to most accurately test the capabilities of area-wide systems for disaster medicine response. The scenario includes multiple moulaged casualties who require evacuation to area hospitals. Activation of field medical resources is used to augment the existing peacetime pre-hospital evacuation resources.

The operational medicine course implemented as an integral part of our emergency medicine residency program was created to fill a void which we perceived existed in more traditional emergency medical training programs. We feel that the course better prepares our residents for roles of leadership and disaster medical management and we strongly recommend its modified implementation into other emergency medical training programs.

\section{Training of Physicians in Disaster Medicine}

\author{
Konrad Hell, MD \\ P. Pike, MD
}

In disasters, every available physician and lay person alike is called upon to render help. Disaster medicine is a most demanding field because of its multidisciplinary nature. Specialties like anesthesia, general surgery, internal medicine, pediatrics, opthalmology, orthopedics, otorhinolaryngology, bacteriology, thoracic and vascular surgery, toxicology, radiology, and others are each separately and directly involved. Without specialized knowledge, no one physician is able to cope with all problems that may arise. Therefore, disaster management planning calls for adequate training and organizational preparations, with plans for the whole spectrum of possible catastrophes from man-made and natural disasters le.g., floods, avalanches, fire, war, terrorism attacks; air, rail and highway accidents; chemical catastrophes, irradiation, and radioactive fallout). Organization covers alarm, transportation, medical help and hospital care. A training program in disaster medicine is essential for every single doctor regardless of his present occupation. The teaching of disaster medicine should start in medical school and be followed by regular post-graduate courses to update this knowledge throughout his or her professional life.

In Switzerland, compulsory courses in disaster medicine are held during medical school for two or three days where all facets of the problem are dealt with, such as: general principles of disaster medicine; organization of help in catastropes; triage and medical first aid in mass casualties; treatment of shock, pain and respiratory distress; life saving emergency operations; special aspects of burns, fractures, head trauma, thoracic lacerations, abdominal injuries, cold damage, infectious disease and polytrauma as they apply to disaster situations; and psychiatric and psychological problems connected with disasters.

\footnotetext{
From the Department of Surgery, University of Basel, Basel, Switzerland. And from the Kantonsspital, Liestal, Baselland, Switzerland. Presented in June 1981; reviewed by authors in 1982.
} 
Furthermore, since every Swiss male is conscripted into the militia, or into civil defense, the male physician in Switzerland has additional professional education during his training. In addition, he will be called for a four day review course in disaster medicine and war surgery every four to six years, up to the age of about 50 years. Those dispensed or discharged from service are required to exercise in compulsory civil defense drills up to the age of 60 years, where courses in medical disaster management are given, including triage and medical treatment under disaster situations. All these efforts aim to ensure the best possible medical treatment in all kinds of catastrophes for the greatest possible number of victims.

In our opinion, the guiding principles which apply to training in disaster medicine are: 1) Always be prepared for disasters; 2 | be organized for all kinds of disasters and have your equipment ready; 3 ) everyone may be involved or be called upon in disasters; 4) everybody needs training for emergencies; 5) every physician must be expert in the medical management of catastrophes, for example, triage and treatment; and 6) review knowledge and skills in disaster management regularly. By following these rules, one may relax until disaster strikes!

In summary, training in disaster medicine for physicians in Switzerland begins during their medical school with a compulsory two to three day course dealing with all aspects of mass casualties and the medical management of disasters. Since every Swiss male is a conscript in the militia, many physicians receive further instruction in disaster medicine during their military service. Review courses for all military physicians up to the age of 50 years are given for four days every four to six years by medical professor in uniform. These efforts are intended to ensure the best possible medical and surgical treatment in all kinds of mass catastrophes and disasters for the greatest possible number of victims, under all imaginable circumstances, with special reference to triage and emergency measures.

\section{Example of Education in Disaster Medicine in Sweden}

\author{
Hans Nordstrom, MD \\ Ulf Bergkvist, $M D$
}

Sweden has not been at war since 1809-1810, when we fought against Russia in Finland. Lyrics by Runeberg are among the few documentations about the wounded in that war. Life-saving first aid was not very good at that time, and most of the wounded died. Modern Sweden is a technically advanced community. We have had some mass casualty situations, such as fires in restaurants and airplane accidents. Six months ago a train crashed just outside the fire brigade station, only five minutes running distance from the hospital. The result was one person dead, two severely injured and about 40 slightly injured. The same crash could have occurred elsewhere in Sweden where the situation might have been much worse, for much of Sweden is very deserted with large woods, and roads are scarce.

At the same time, most of our doctors and their medical personnel are accustomed to working in technically wellequipped hospitals and they lack "active service fitness." That is to say, they have no experience of working in different milieus and they are not used to working together with other professional groups who might wish to dominate the situation. Therefore, we have found it necessary to put the different groups in the rescue service together and give them an education in disaster management.

At first, we investigated how other countries with greater experience have solved this problem. In Sweden, we have a special organization, CAMEDO, the organization committee of medical disaster planning, to perform this work and produce written information.

In our medical schools, during the fourth year, there is one week devoted to teaching students disaster medicine. Earlier, this one week course was mainly information about military medicine and medical problems in developing countries, and not much about practical medical management, especially not about life-saving first aid and

From the University Hospital of Linköping, Sweden.
Presented in June 1981 ; reviewed by author in 1982 . 